\title{
An Adaptive Reclosing Strategy for MMC-HVDC Systems with Hybrid DC Circuit Breakers
}

\author{
Saizhao Yang, Wang Xiang, Member, IEEE, Xiaojun Lu, Member, IEEE, Wenping Zuo, Jinyu Wen, Member,
} IEEE

\begin{abstract}
Modular multilevel converter (MMC) based high voltage direct current transmission (HVDC) is an effective solution for large-scale renewable power integration over long-distance. In the overhead MMC-HVDC systems, the high voltage DC circuit breakers (DCCB) are implemented to interrupt the DC fault current. Subsequent to fault isolation, the DCCBs are required to automatically re-close to restore power transmission quickly. However, when the DCCBs are re-closed to permanent faults, they will be tripped again, resulting in a high requirement of interruption capacity for DCCBs and second overcurrent strikes on the HVDC systems. To overcome the drawbacks of the conventional auto-reclosing scheme, this paper proposes an adaptive reclosing scheme based on the active pulse injection from the converter associated with the coordination control of hybrid DCCBs. The single-end adaptive reclosing scheme as well as the two ends adaptive reclosing scheme dedicated to two-terminal HVDC systems and meshed DC grids are presented respectively. By applying this method, the location of faults can also be achieved in the case of permanent faults. In order to verify the effectiveness of the proposed adaptive reclosing schemes, extensive simulations have been conducted under PSCAD/EMTDC.
\end{abstract}

Index Terms-MMC-HVDC, DC grids, DCCB, adaptive reclosing, fault location, traveling wave.

\section{INTRODUCTION}

Modular multilevel converter based high voltage direct current (MMC-HVDC) transmission systems are widely recognized as a promising approach to transmit large-scale renewable energy over long distance [1]. Since the overhead lines (OHL) are vulnerable to DC faults, the DC circuit breakers (DCCB) are implemented to interrupt the fault current. Recently, various DCCB topologies have been proposed. Among them, the hybrid DCCBs based on the mechanical switch and full-controlled power electronics have the merits of high interruption speed and small on-state power loss [2], attracting lots of attention. Several companies have developed some hybrid DCCB prototypes, such as the $80 \mathrm{kV} / 5 \mathrm{~ms} / 9 \mathrm{kA}$ DCCB proposed by ABB, the $120 \mathrm{kV} / 5.2 \mathrm{kA} / 5.5 \mathrm{~ms}$ DCCB proposed by Alstom, the $200 \mathrm{kV} / 15 \mathrm{kA} / 3 \mathrm{~ms}$ DCCB proposed by State Grid Corporation of China and the $500 \mathrm{kV} / 25 \mathrm{kA} / 3 \mathrm{~ms}$ DCCB proposed by Nanrui group [3]-[6]. The last two types of hybrid DCCBs will be applied to the $\pm 500 \mathrm{kV}$ MMC based overhead DC grid Zhangbei project, which will be commissioned in 2020 [7].

To ensure power system stability, the HVDC systems are required to be able to recover power transmission quickly [8].

This work is sponsored by the National Natural Science Foundation of China (51807071 and U1766211). (Corresponding author: Wang Xiang)

S. Yang, W. Xiang, X. Lu, W. Zuo, J. Wen are with the State Key Laboratory of Advanced Electromagnetic Engineering and Technology, Huazhong University of Science and Technology, Wuhan 430074, China. (email: saizhaoyang@foxmail.com, xiangwang1003@foxmail.com, luxiaojun @hust.edu.cn,radio.zuo@foxmail.com,jinyu.wen@hust.edu.cn).
The conventional post-fault recovery strategy for the MMCHVDC systems embedding DCCBs is originated from the AC power system. Namely, after the arc deionization of faulted OHLs, the DCCBs will be automatically re-closed within a predetermined time [8]. In the case of reclosing to permanent faults, the system will subject to DC faults again and therefore suffer from second strikes [9]. Unlike AC circuit breakers (ACCB) tripping fault current at zero crossing point, the twicetripping of DCCB leads to a higher requirement of interruption capacity. Taking Zhangbei project as an example, the maximum dissipated energy of a DCCB at Zhangbei station is around $90 \mathrm{MJ}$ during the first trip [10]. When DCCBs are re-closed to a permanent fault, DCCBs should absorb nearly 100MJ extra energy during the second trip, which brings increasing challenges to the configuration of arresters and the design of DCCB main circuit.

To avoid second damage to the HVDC system and reduce the interruption capacity of DCCBs, it is better to identify the fault characteristic (non-permanent or permanent) prior to DCCB reclosure. If the fault is assessed to be permanent, the DCCB will not be re-closed, thereby achieving the adaptive reclosing capability [11]. As for the AC systems, the single-phase and three-phase adaptive reclosure schemes can be designed according to the coupled effects between faulted phases and healthy phases and the fault characteristics of shunt reactors respectively [12]-[15]. However, for the HVDC systems, there is no shunt reactor on the OHLs and the electrical coupling between the healthy lines and faulted lines is weak [19]. Thus, the adaptive reclosing schemes used in AC systems are not suitable for the DC systems.

With regard to the design of adaptive reclosing schemes for MMC-HVDC systems, several publications provide some methods based on active control of DCCBs or converters. Reference [8] proposes a fast recovery strategy by active control of the insertion of sub-modules (SM) for the selfblocking MMC. A soft reclosing model (SRM) for the half bridge MMC with hybrid DCCBs is proposed in [16]. During the reclosing process, an additional $1500 \Omega$ resistance will be inserted into the DC system. Though the second overcurrent strike under permanent faults is mitigated, there will be a strike when the additional resistance is bypassed under nonpermanent faults. A sequential auto-reclosing method for hybrid DCCB is proposed in [17]. But this method still brings about large dissipation requirement of DCCBs, which will reduce the life time of DCCBs. Reference [18] proposes an adaptive reclosing strategy for full-bridge MMC-HVDC system. The nonlinear interdependence between the fault resistance and the current is used to detect nonpermanent faults. However, this method cannot be applied to half-bridge MMCs. And the sensitivity to 
This paper is a post-print of a paper submitted to and accepted for publication in IEEE Transaction on Power Delivery and is subject to Institution of Electrical and Electronic Engineering Copyright. The copy of record is available at IEEE Xplore Digital Library

high-resistance faults is weak. Reference [19] puts forward an active reclosing scheme for MMC- HVDC systems with fullbridge cascaded DCCB [5]. By switching on specific fullbridge SMs embedded in DCCBs, a voltage pulse is generated and injected into the faulted line. On detecting the traveling voltage wave on the OHL, the fault characteristics can be identified. However, this method is restricted to the full-bridge cascaded DCCB topology and lacks the detailed analysis of traveling waves. A method for fault location based on active pulse injection from MMC is proposed in [20]. Different from the approach in [19], the injected pulse in [20] is generated by changing the insert number of half-bridge (HB) SMs in one phase unit. This method is on the basis that the control system of MMC still operates normally during single pole to ground (PTG) fault. However, when single PTG faults occur, the DC voltage of the healthy pole will increase to two times of the rated voltage quickly, resulting in activation of the protection system and shut down of the control system [21].

To overcome the shortcomings of the aforementioned methods, this paper proposes an adaptive reclosing strategy for MMC-HVDC systems embedding hybrid DCCBs. It takes advantages of active control of MMC and coordination control of hybrid DCCBs to inject a temporary voltage pulse into the faulted lines. Based on the traveling wave theory, a low-voltage based criterion is designed to identify the fault characteristics. This method is robust to fault resistances and fault types. Moreover, the fault location can also be achieved using the traveling wave method.

The remainder of the paper is structured as follows. Section II explains the traditional auto-closing scheme of the MMCHVDC systems. In section III, the adaptive reclosing schemes dedicated to two-terminal HVDC systems and meshed DC grids are designed respectively. The traveling wave theory based fault identification method is presented in section IV. Then, the criteria for the fault identification and fault location are designed in section $\mathrm{V}$. The effectiveness and robustness of the proposed methods are verified under extensive cases in section VI and VII. Besides, adaptive reclosing schemes using two ends voltage pulse injection methods are analyzed and discussed in section VIII. Finally, the conclusion remarks are drawn in section IX.

\section{AUto-RECLOSING SCHEME FOR HB MMC-HVDC SYSTEMS}

\section{A. System Layout of HB MMC-HVDC System}

Fig. 1 shows a typical bipolar MMC-HVDC topology with a metallic return line. The converters MMC1P, MMC1N, MMC2P and MMC2N adopt the half-bridge MMC topology. The DCCBs are installed at the DC terminal of each converter to isolate DC fault lines. The DC current-limiting reactors are also implemented on the OHLs to limit the fault current rise rate.

The DCCBs shown in Fig. 1 adopt the hybrid DCCB topology proposed by ABB. It consists of the main branch, the transfer branch and the absorb branch in parallel connection, as shown in Fig. 2. The main branch consists of the load commutation switch (LCS) and the ultra-fast disconnector
(UFD). The transfer branch is composed of a large number of series IGBTs. To mitigate the switch-on dispersibility of the IGBTs, the snubber circuit is adopted in parallel with the IGBTs. The absorb branch consisted of multiple arresters in series is used to dissipate the fault energy and suppress the overvoltage in the breaking process [22].

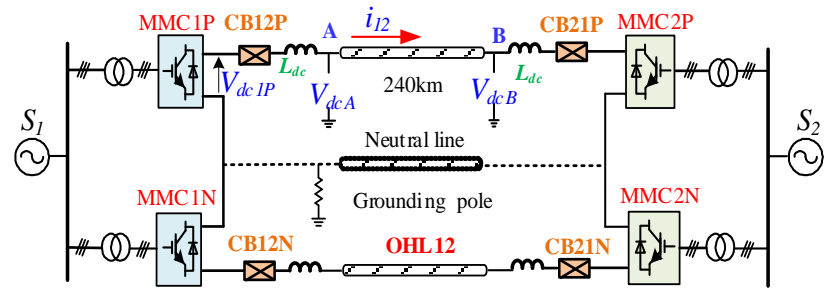

Fig. 1. The topology of a bipolar MMC-HVDC system.

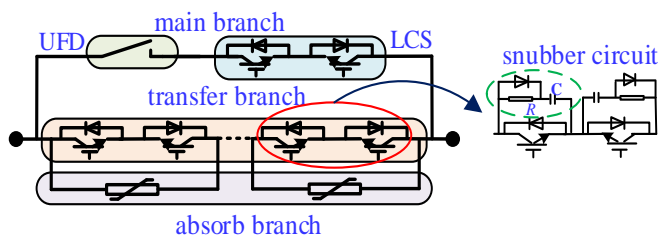

Fig. 2. The topology of hybrid DCCB.

Each MMC adopts the conventional double closed-loop vector control scheme, as shown in the blue box of Fig. 3. The sending end (MMC1) controls the DC link voltage of the HVDC system while the receiving end (MMC2) controls the transmitted power.

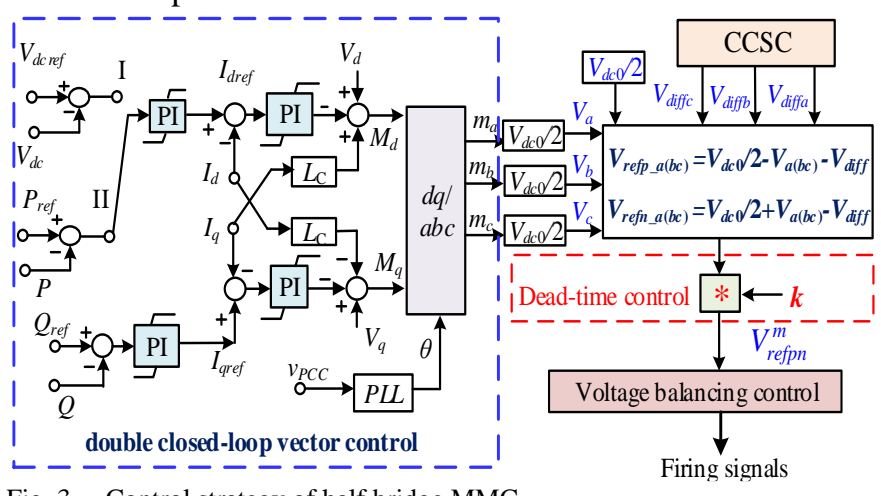

Fig. 3. Control strategy of half bridge MMC.

\section{B. Auto-Reclosing Scheme of HB MMC-HVDC System}

The conventional auto-reclosing scheme originated from the AC system is depicted in Fig. 4 [23].

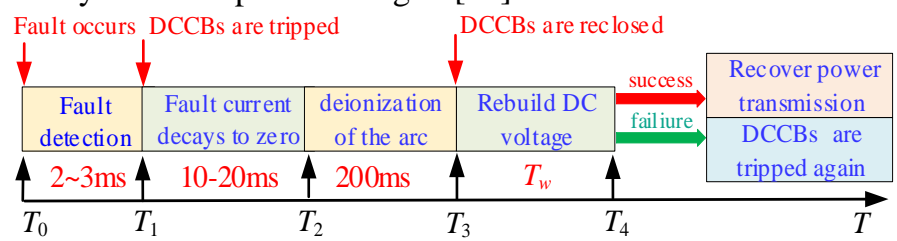

Fig. 4. The time sequence of the auto-reclosing scheme.

At time $T_{0}$, the system is subjected to a DC line fault. When the fault is detected, the tripping orders are sent to DCCBs. The time delay of detection process is within $2-3 \mathrm{~ms}$. Subsequent to the DCCB tripping, the fault current will decrease within $3 \mathrm{~ms}$ and decay to zero within 10-20ms. After deionization of arc (usually $200-300 \mathrm{~ms}$ ), the DCCBs are automatically re-closed. Then, the DC voltage of the faulted line is measured to assess whether the fault still exists. If the DC voltage rebuilds to a large value within a certain time, it is deemed that the fault is 
This paper is a post-print of a paper submitted to and accepted for publication in IEEE Transaction on Power Delivery and is subject to Institution of Electrical and Electronic Engineering Copyright. The copy of record is available at IEEE Xplore Digital Library

cleared and the reclosing is successful. Otherwise, if the DC voltage is still a small value (according to the fault resistances), the fault is identified to be permanent and DCCBs will be tripped again.

Though the auto-reclosing scheme is easy to be implemented, it increases the interruption capacity of DCCBs and the risk of converters.

\section{AdAPTIVE ReClosing Schemes}

To avoid second strike to the HVDC systems, an alternative way is to identify the fault characteristic prior to DCCB reclosure. This paper takes advantages of the controllability of MMC and hybrid DCCB to realize active pulse injection. Firstly, a voltage pulse is generated by the MMC and injected into the faulted lines. To provide a conduction path for the injected pulse, the transfer branch of hybrid DCCB will be switched on for a short time. Then, by comparing with the refracted waves under non-permanent and permanent DC faults, the fault characteristics can be identified. Since the topologies of HVDC systems determine the voltage pulse injection capability of converters, the adaptive reclosing schemes dedicated to two-terminal HVDC systems and meshed DC grids will be presented respectively.

\section{A. Adaptive Reclosing Strategy for the Two-Terminal HB MMC-HVDC System}

Taking the two-terminal HB MMC-HVDC system shown in Fig. 1 as an example, the reference voltage of each arm of MMC is determined by the output of double closed-loop vector control under normal operation. During tripping of DCCBs, the output DC voltage of MMC fluctuates due to the fault transients. After the isolation of faulted lines, the power transmission is interrupted and the output DC terminal voltage of MMC restores to around the rated value. To facilitate adaptive reclosing, a dead-time control is employed to generate a controllable voltage impulse, as shown in the red box of Fig. 3 . Once the dead-time control is triggered, the reference voltages of upper and lower arms $\left(V_{\text {refp_a }}, V_{\text {reff_a }}\right)$ are modified as (taking phase $A$ of MMC1P as an example):

$$
\left\{\begin{array}{l}
V_{\text {refp_a }}^{m}=k V_{\text {refp_a }}=k\left(V_{d c 0} / 2-V_{a}-V_{\text {diffa }}\right) \\
V_{\text {refn_a }}^{m}=k V_{\text {refn_a }}=k\left(V_{d c 0} / 2+V_{a}-V_{\text {diffa }}\right)
\end{array}\right.
$$

where the superscript " $m$ " denotes the modified value. $V_{d c 0}$ is the rated DC terminal voltage and $V_{a}$ is the AC reference voltage of phase $A$. $k$ is the proportionality coefficient, defined as:

$$
\left\{\begin{array}{c}
k=1 ; \quad \text { all other time } \\
0<k<1 ; \text { during pulse injection }
\end{array}\right.
$$

During the short pulse injection period, the number of inserted sub-modules in one phase will become $k$ times of that under normal operation. Since the duration time of the deadtime control is very short, the discharge of sub-module capacitors can be neglected. Neglecting the voltage drop on DC current-limiting reactors, the output DC terminal voltage of MMC can be approximated as:

$$
V_{d c}^{m}=k V_{d c o}
$$

Therefore, a controlled voltage pulse is generated. Since DCCBs are turned off during fault isolation, there is no conduction path for the generated voltage pulse to inject into the faulted line. Thus, coordination control is proposed for the hybrid DCCB. When the dead time control activates to generate the injected voltage pulse, considering the fast control speed of full-controlled power electronics, the transfer branch (TB) is turned on for a short period to provide the propagation path.

The detailed states of DCCB and converter during the adaptive reclosing is shown in Fig. 5. After deionization of OHLs, MMC shifts to dead-time control. A voltage pulse with an amplitude of $k V_{d c 0}$ is generated. Meanwhile, the transfer branch of DCCB is turned on and lasts for $\Delta t_{p u l s e}$ time to provide a conduction path for the injected pulse. Then, the transfer branch is turned off and the refracted waves on the OHL are measured for the fault identification.

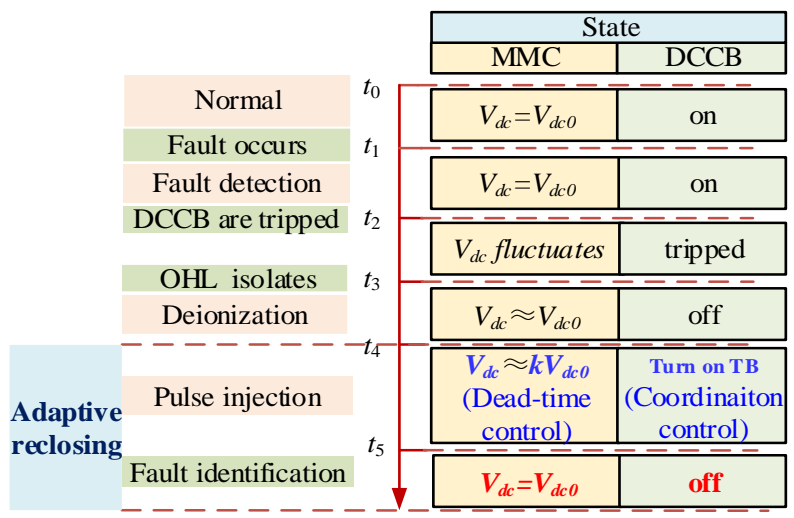

Fig. 5. The states of DCCB and converter during the adaptive reclosing.

B. Adaptive Reclosing Strategy for the MMC based Meshed DC Grid

Fig. 6 shows a typical meshed MMC based DC grid topology, where station $\mathrm{MMC} 1$ controls the DC voltage and reactive power and MMC2-MMC4 control the active and reactive power. The hybrid DCCBs are installed at the terminals of each overhead lines.

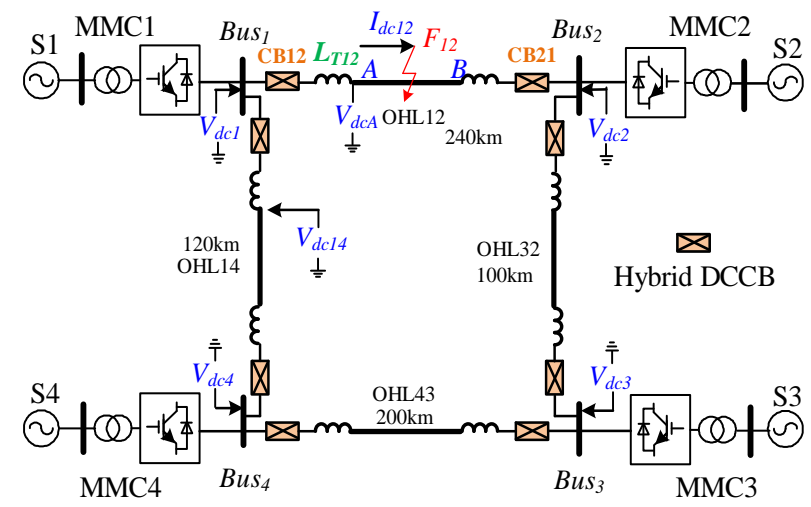

Fig. 6. Topology of the four-terminal MMC based DC grid.

The adaptive reclosing strategy for the DC grids can also be realized by injecting a voltage pulse into the faulted lines and turning on the TBs of DCCBs for a short time. Then, the fault characteristics can be identified depending on the measured refracted waves. However, different with the two-terminal HVDC system, the generated voltage pulse from one converter may interfere the adjacent stations through the healthy lines. 
This paper is a post-print of a paper submitted to and accepted for publication in IEEE Transaction on Power Delivery and is subject to Institution of Electrical and Electronic Engineering Copyright. The copy of record is available at IEEE Xplore Digital Library

Moreover, uninterrupted power transmission is one of the main concerns in meshed DC grids. Supposing a DC fault happens on OHL 12, after isolation of OHL 12, the DC line voltage of the DC grid is re-established by MMC1 and active power can be transmitted to the receiving ends through remaining overhead lines OHL14, OHL43 and OHL32. To not interrupt the power transmission, the injected voltage pulse should not be designed arbitrarily.

\section{Parameter Design of the Injected Voltage Pulse}

The amplitude of injected voltage pulse should take into account the effects on the traveling wave detection and impact on the remaining parts.

For the two-terminal MMC HVDC system, since power transmission is interrupted, avoiding second overcurrent is of the top concern. Thus, the amplitude of injected voltage pulse should be small. However, to detect the refracted traveling wave better and resist to noise disturbance, the amplitude should be a relatively large value. In this paper, it is suggested that the amplitude of injected pulse $V_{I w}$ is $2 \%$ 10\% of the rated DC voltage. Thus, the amplitude of injected pulse $V_{l w}$ is $20 \mathrm{kV}$. And $k$ is selected as 0.04 .

For the MMC based DC grids, referring to equation (1), if the DC voltage station shifts to dead-time control, the DC line voltage of the whole grid will collapse, leading to interruption of power transmission. If the power station shifts to dead-time control, it will also hinder the transmitted power. To not interrupt the remaining parts, the coefficient $k$ should be equal to 1 all the time. Thus, to realize adaptive reclosing, it only needs to turn on the transfer branch. Then, the DC line voltage will also generate a voltage pulse, and it will be injected into the faulted lines.

The duration of dead-time control should cooperate with the turning-on time of transfer branch. If the turning-on time $\Delta t_{p u l s e}$ is too large, the wave end of the injected pulse may overlap with the wave-front of the reflected wave under faults close to the terminals. To reduce the stress on power electronics during reclosing, $\Delta t_{p u l s e}$ should be as small as possible. However, the value of $\Delta t_{\text {pulse }}$ is limited by the sampling frequency, the control period, and the IGBT switching frequency of DCCB. Taking Zhangbei project as an example, the sampling interval of the control and protection is $50 \mu$ s and $20 \mu$ s respectively [24]; the switching frequency of the IGBT is as high as $10 \sim 40 \mathrm{kHz}$. Considering the constraints, $\Delta t_{\text {pulse }}$ can be chosen as $100 \mu \mathrm{s}$. To make sure the injected pulse is controllable during $\Delta t_{\text {pulse }}$, the duration time of dead-time control in the two-terminal HVDC case should be a little larger than $\Delta t_{\text {pulse }}(0.15 \mathrm{~ms}$ in this paper).

\section{Fault Identification based on TRAVELING WaVe}

\section{A. Traveling Wave Analysis under Permanent Faults}

After generation of voltage pulse, it will propagate along the faulted lines. Fig. 7 illustrates the propagation process. Supposing a voltage pulse $V_{l w}$ is injected into the OHL and propagates from node $A$ towards node $B$. Applying a permanent fault at node $C$, due to the physical boundary, $V_{l_{w}}$ will be reflected and refracted at node $C$. The refracted wave $V_{C l w}$ continues to propagate towards node $B$ while the reflected wave $V_{C l f}$ propagates to node $A$. Based on the traveling wave analysis, we have

$$
\left\{\begin{array}{l}
V_{C l f}=\beta_{C} V_{l w}=\frac{Z_{2}-Z_{l}}{Z_{2}+Z_{l}} V_{l w}=\frac{R_{g} \| Z_{C}-Z_{C}}{R_{g} \| Z_{C}+Z_{C}} V_{l w} \\
V_{C l w}=\alpha_{C} V_{l w}=\frac{2 Z_{2}}{Z_{2}+Z_{l}} V_{l w}=\frac{2 R_{g} \| Z_{C}}{R_{g} \| Z_{C}+Z_{C}} V_{l w}
\end{array}\right.
$$

where $\alpha_{C}$ and $\beta_{C}$ represent the refraction coefficient and the reflection coefficient of node $C$ respectively. $Z_{C}$ represents the wave impedance. Its typical value is within the range of $(230 \Omega$ $-380 \Omega$ ) [25]. $R_{g}$ represents the fault resistance. $Z_{l}$ is the equivalent wave impedance of the transmission line where the traveling wave first propagates. $Z_{2}$ is the equivalent wave impedance of the transmission line where the traveling wave refracts and reflects. In equation (4), the traveling wave will be refracted and reflected at point $C$ due to the fault resistance. Thus, $Z_{I}=Z_{C}$ and $Z_{2}=Z_{C} / / R_{g}$. Since the amplitude of $V_{C l f}$ is related to the fault resistance $R_{g}$, the following analysis will be carried out according to different fault resistances.

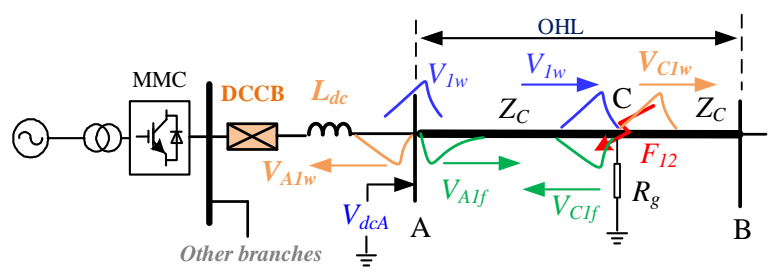

Fig. 7. Process of reflection and refraction the traveling waves.

1) Low-Resistance Fault Scenarios

Referring to equation (4), under low-resistance faults (particularly for metallic faults), it can be approximated as

$$
\left\{\begin{array}{c}
V_{C l f}=\beta_{C} V_{l w} \approx \frac{0-Z_{C}}{0+Z_{C}} V_{l w}=-V_{l w} \\
V_{C l w}=\alpha_{C} V_{l w} \approx \frac{0}{0+Z_{C}} V_{l w}=0
\end{array}\right.
$$

Equation (5) indicates that under low-resistance fault, a total negative reflection of $V_{l w}$ occurs at node $C$. Thus, the traveling wave is only reflected and refracted between node $A$ and node $C$. After a propagation delay $\Delta t$, the reflected wave $V_{C l f}$ arrivals at node $A$, and it will be reflected again $\left(\Delta t=D_{\text {fault }} / v, D_{\text {fault }}\right.$ denotes the distance from node $A$ to node $C$ and $v$ presents the propagation speed of the traveling wave).

Denote $\alpha_{A}$ and $\beta_{A}$ as the refraction and reflection coefficients at node $A$ respectively. Considering that DCCB is turned off, $\mathrm{Z}_{2}$ is infinite. Hence, $\alpha_{A}$ and $\beta_{A}$ are obtained.

$$
\left\{\begin{array}{l}
\alpha_{A}=\frac{2 Z_{2}}{Z_{2}+Z_{1}}=\frac{2 \infty}{\infty+Z_{C}}=2 \\
\beta_{A}=\frac{Z_{2}-Z_{1}}{Z_{2}+Z_{1}}=\frac{\infty-Z_{C}}{\infty+Z_{C}}=1
\end{array}\right.
$$

Denote that the first detected refracted wave at node $A$ is $V_{A I w}$. Based on equations (5)-(6), the refracted wave $V_{A I w}$ is equal to $\alpha_{A} \beta_{C} V_{l w}\left(2 \beta_{C} V_{l w}\right)$ while the reflected wave $V_{A l f}$ is equal to $\beta_{A} \beta_{C} V_{l w}\left(\beta_{C} V_{l w}\right)$. Since $\beta_{C}$ is negative (approximately equal to -1), the polarity of $V_{A I w}$ reverses. Similar to $V_{I w}$, the reflected wave $V_{A l f}$ propagates towards node $B$, and will be reflected at node $C$ again. After the propagation delay $\Delta t$, the second refracted voltage equals to $2 \beta_{C}^{2} V_{l w}$ is detected at node $A$. 
This paper is a post-print of a paper submitted to and accepted for publication in IEEE Transaction on Power Delivery and is subject to Institution of Electrical and Electronic Engineering Copyright. The copy of record is available at IEEE Xplore Digital Library

Similarly, the third, fourth, and fifth ... refracted voltage waves $V_{I w}$ is positive, the polarities of the voltage waves detected at detected at node $A$ are $2 \beta_{c}^{3} V_{l w}, 2 \beta_{c}^{4} V_{l w}, 2 \beta_{C}^{5} V_{l w} \ldots$ respectively. Fig. 8 (a) shows a schematic diagram of refraction and node $A$ are successively negative, positive, negative ..., as shown in Fig. 9 (a). reflection process between node $A$ and node $C$. Supposing that

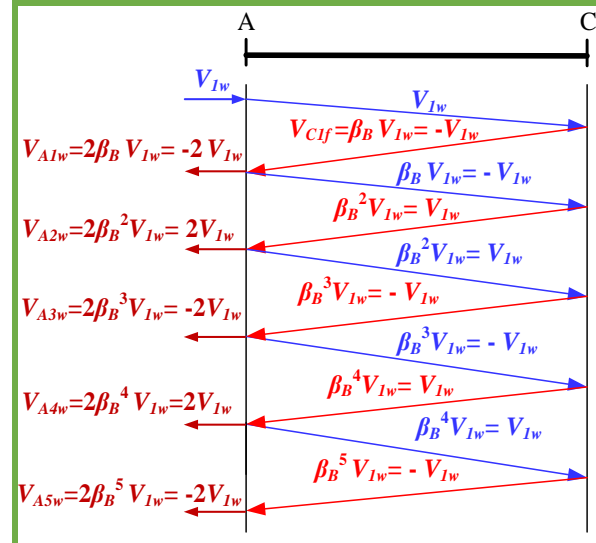

(a) permanent faults with low resistance

Fig. 8. Refraction and reflection process under different faults.

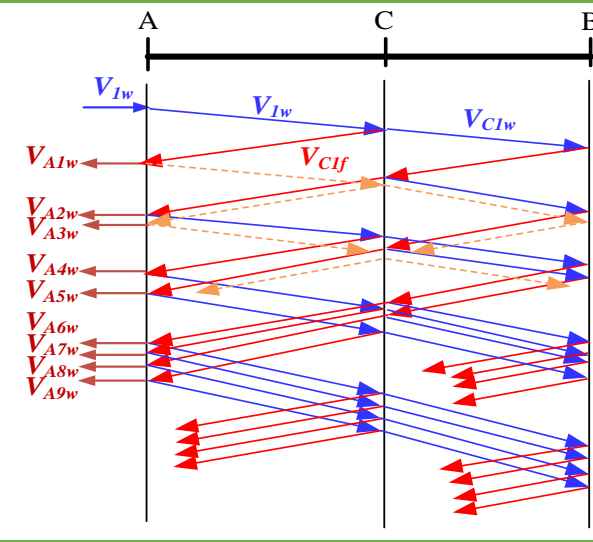

(b) permanent faults with high resistance

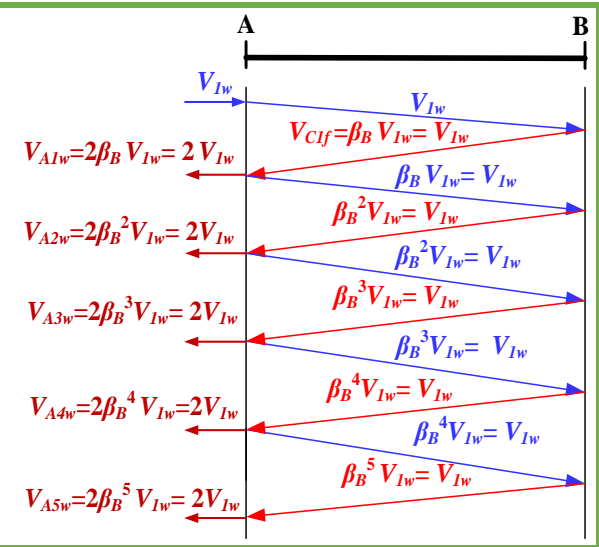

(c) non-permanent faults

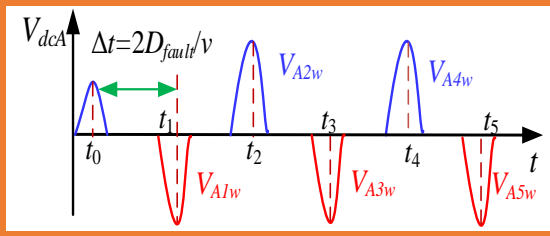

(a) permanent faults with low resistance

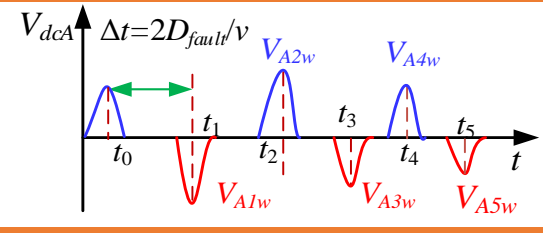

(b) permanent faults with high resistance

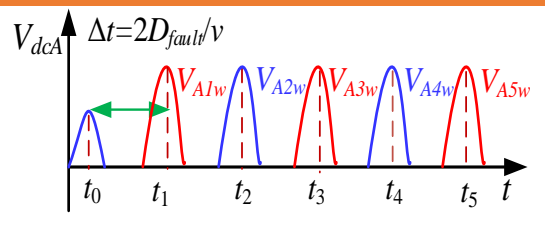

(c) non-permanent faults Fig. 9. The waveform of voltage $V_{d c A}$ under different faults.

2) High-Resistance Fault Scenarios

In the event of high-resistance faults, equation (5) is no longer valid. Thus, the traveling wave will be reflected between $\mathrm{AC}$ and $\mathrm{BC}$, making the analysis of traveling wave process much complicated, as shown in Fig. 8(b). In addition, the fault distance will also affect the traveling waves. On considering the polarities of the refracted waves, Fig. 9(b) shows the waveform of $V_{d c A}$ when a permanent fault with high resistance happens in the middle of OHL12.

For permanent faults, the first detected voltage at node $A$ is always the refracted wave $V_{A l w}$ that is equal to $2 \beta_{C} V_{l w}$, regardless of the fault resistance. Considering that the parallel impedance $Z_{2}\left(Z_{2}=R_{g} / / Z_{C}\right)$ is smaller than the impedance $Z_{C}$, the reflection coefficient $\beta_{C}$ is always negative. As a result, $V_{A l w}$ is always negative under permanent faults.

\section{B. Traveling Wave Analysis under Non-Permanent Faults}

In the event of non-permanent faults, there is no fault providing a boundary condition. Thus, the traveling wave propagates directly to node $B$, as shown in Fig. 8(c). Since the DCCBs at node $B$ and node $A$ are turned off, there exist total positive reflections at both node $A$ and node $B\left(\alpha_{A}=\alpha_{B}=2\right.$, $\beta_{A}=\beta_{B}=1$ ). As a result, polarities of the voltages measured at node $A$ are always positive, as shown in Fig. 9(c).

In summary, polarities of voltage $V_{A l w}$ under different fault characteristics are opposite, which provides a feasible approach for fault identification. And it should be noted that the above analysis is applicable to both two-terminal HVDC and DC grid cases.

\section{CRIteria Design for Fault IdENTIFication AND Fault LOCATION}

\section{A. Criteria Design for Fault Identification}

According to the aforementioned analysis, the detected refracted voltage $\left(V_{A I w}\right)$ at node $A$ is always positive under non-permanent faults while it is negative under permanent faults. Thus, a low voltage criterion can be designed for the fault identification.

Denote $t_{0}$ as the moment when $V_{l w}$ is detected and $t_{l}$ as the moment when refracted wave $V_{A l w}$ arrives at node $A$. The detection time $t_{d}\left(t_{d}=t_{1}-t_{0}\right)$ of $V_{A l w}$ is no more than $2 D_{\mathrm{AB}} / v$ under permanent faults. Taking the measurement error into account, a certain margin of $0.5 D_{\mathrm{AB}} / v$ is considered. Thus, the fault identification algorithm based on low voltage and detection time criteria can be designed

$$
V_{A l w}<V_{\text {set }} \text { and } t_{d}<\left(2 D_{A B} / v+0.5 D_{A B} / v\right)
$$

where $V_{\text {set }}$ is the setting threshold of the low-voltage criterion. It is suggested to be a negative value.

Referring to the above analysis, $V_{A l w}$ during permanent faults can be calculated as

$$
V_{A l w}=\alpha_{A} \beta_{C} V_{l w}=2 \beta_{C} V_{l w}=\frac{-Z_{C}}{R_{g}+Z_{C} / 2} V_{l w}
$$

Equation (8) indicates that the amplitude of $\left|V_{A I w}\right|$ decreases with the increase of $R_{g}$, so the maximum value of $V_{A l w}$ (negative) can be obtained

$$
V_{A l w \max }=-\frac{Z_{C}}{R_{g \max }+Z_{C} / 2} V_{l w}
$$

Considering a reliability coefficient $k_{r e l}, V_{\text {set }}$ can be 
This paper is a post-print of a paper submitted to and accepted for publication in IEEE Transaction on Power Delivery and is subject to Institution of Electrical and Electronic Engineering Copyright. The copy of record is available at IEEE Xplore Digital Library

designed as $V_{\text {set }}=k_{\text {rel }} \times V_{\text {Alwmax }}$.

\section{B. Fault Location based on Modulus Maxima}

A simplified diagram of traveling wave propagation path is shown in Fig. 10. As can be seen, the injected pulse $V_{l w}$ propagates towards node $B$ and is reflected at node $\mathrm{C}$. Then, the reflected wave $V_{C I f}$ propagates back to node $A$. Since the traveling wave travels at nearly light speed on the OHL, the fault location can be achieved by calculating the time interval between injected pulse and refracted pulse (namely the detection time $t_{d}$ ).

$$
\begin{aligned}
& D_{\text {fault }}=\frac{1}{2} \times t_{d} \times v=\frac{1}{2} \times t_{d} \times 3 \times 10^{8}
\end{aligned}
$$

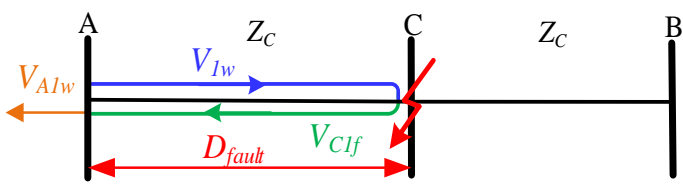

Fig. 10. The simplified diagram of the traveling wave propagation path.

To improve the accuracy of fault location, the modulus maxima (MM) is adopted to realize the measurement of detection time $t_{d}$, as defined in the following equation

$$
V_{M M}=V_{t} \text {, if }\left|V_{t^{-}}\right|<\left|V_{t}\right| \text { and }\left|V_{t^{+}}\right|<\left|V_{t}\right|
$$

As shown in Fig. 11, $V_{O M M}$ and $V_{I M M}$ denote the MMs of $V_{I W}$ and $V_{A 1 w}$ respectively. By measuring the occurrence time of $V_{O M M}$ and $V_{I M M}$, the detection time $t_{d}$ can be obtained $\left(t_{\mathrm{d}}=t_{1}-t_{0}\right)$.

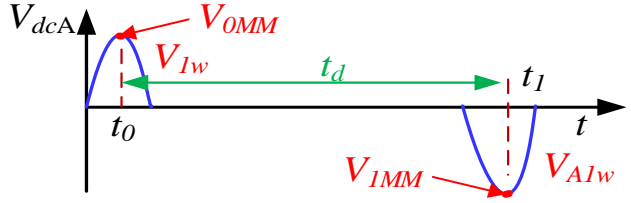

Fig. 11. Measurement of $t_{d}$ based on modulus maxima.

\section{SIMULATION AND VERIFICATION}

In order to verify the feasibility and effectiveness of the proposed adaptive reclosing schemes, a two-terminal MMCHVDC system shown in Fig. 1 and a four-terminal $\pm 500 \mathrm{kV}$ MMC based DC grid shown in Fig. 6 are built in PSCAD/EMTDC. To accelerate the simulation speed, the DC grid system adopts the symmetric monopole configuration. The current-limiting reactor is selected as $0.15 \mathrm{H}$. The other system parameters and converter parameters are listed in Table 1 and Table 2 respectively. The overhead lines adopt the frequency dependent model provided by PSCAD.

Table 1 Parameters of the systems in two-terminal HVDC case

\begin{tabular}{l||c|c|c}
\hline Converters & DC voltage/kV & AC voltage $/ \mathrm{kV}$ & Rated power/MW \\
\hline MMC1P(N) & 500 & 220 & 3000 \\
MMC2P(N) & 500 & 220 & 3000 \\
\hline Converters & arm inductance/mH & SM capacitor/mF & SM number $/ N$ \\
\hline MMC1P(N) & 96 & 15 & 200 \\
MMC2P(N) & 144 & 10 & 200 \\
\hline
\end{tabular}

Table 2 Parameters of each converter in DC grid case

\begin{tabular}{c||cccc}
\hline Converter & MMC1 & MMC2 & MMC3 & MMC4 \\
\hline arm inductance / $\mathrm{mH}$ & 96 & 144 & 115 & 192 \\
sub-module capacitor / $\mathrm{mF}$ & 15 & 10 & 12.5 & 8 \\
sub-module number / $N$ & 200 & 200 & 200 & 200 \\
rate power / MW & 3000 & 2000 & 1500 & 1500 \\
\hline
\end{tabular}

A. Validation of Adaptive Reclosing for Two-Terminal MMC HVDC system

1) Determination of Setting Value for Fault Identification
Applying a pole to pole (PTP) fault in the middle of OHL12 at $1.5 \mathrm{~s}$. Around $1.7 \mathrm{~s}$, the active adaptive reclosing begins. MMC1P and MMC1N shift to dead-time control. In this simulation, the coefficient $k$ is selected as 0.04 . The output DC voltage of MMC1P and $V_{d c A}$ during the reclosing are shown in Fig. 12.

As can be seen in Fig. 12 (a), the amplitude of the injected voltage generated by $\mathrm{MMC} 1 \mathrm{P}$ is $20.88 \mathrm{kV}$, very close to $k V_{d c 0}$ $(20 \mathrm{kV})$. Considering the voltage change on the currentlimiting reactor, the voltage pulse injected into the OHL12 is no longer a square wave, as shown in Fig. 12 (b). It can be seen that the actual voltages of the pulses injected into the positive and negative poles of OHL12 is $24.78 \mathrm{kV}$ and $-24.93 \mathrm{kV}$ respectively. However, since the fault identification scheme mainly relies on the polarities of refracted pulses, the small distorted injected voltage waveform will have no impact on the identification result.
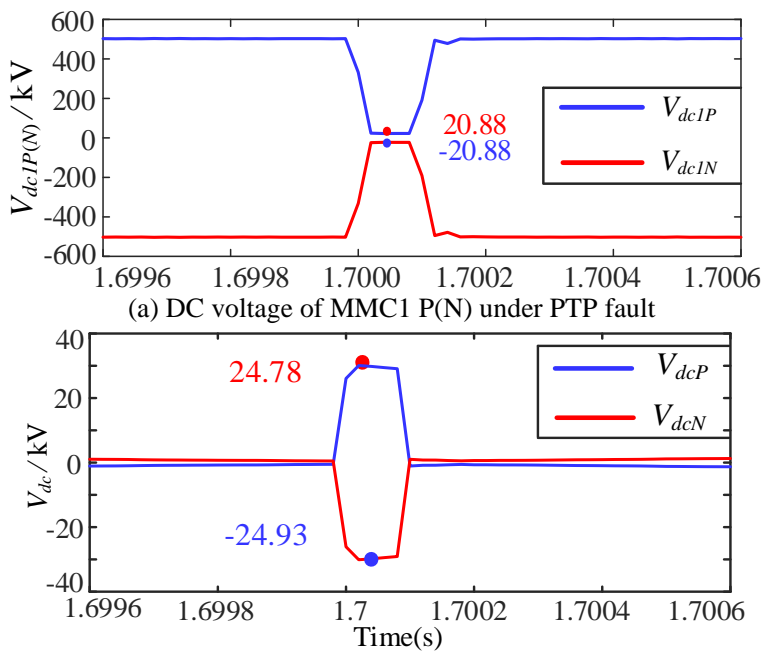

(b) Actual injected voltage under PTP fault Fig. 12. Waveforms of the injected pulse under PTP fault.

According to equation (8), the amplitude of $\left|V_{A l w}\right|$ decreases with the increase of $R_{g}$. Besides, the distance has a small influence on the amplitude of $\left|V_{A 1 w}\right|$. Scanning the faults with different distances, it can be found that the amplitude of $\left|V_{A 1 w}\right|$ under the fault at the end of OHL12 is smallest. Considering the worst condition, i.e. fault happened at the end of OHL12 with high resistance. For PTP fault with $200 \Omega$ resistance, $V_{\text {Alwmax }}$ is $-17.11 \mathrm{kV}$; for PTG fault, $V_{\text {Alwmax }}$ is $12.68 \mathrm{kV}$. Selecting the reliability coefficient $k_{r e l}$ as 0.6 , the setting value $V_{\text {set }}$ is $-12.68 \times 0.6 \approx-8 \mathrm{kV}$.

2) Performance under Metallic Permanent PTP Faults

At $1.5 \mathrm{~s}$, a metallic permanent PTP fault is applied in the middle of OHL12. After 3ms detection delay, DCCB 12P(N) and DCCB $21 \mathrm{P}(\mathrm{N})$ are tripped. The fault current gradually decreases to zero. After deionization of OHL12, MMC1P and MMC1N shift to dead-time control around 1.7s. Meanwhile, the transfer branch of DCCB 12 is turned on for $100 \mu$ s. The voltage and current measured at node $A$ are shown in Fig. 13. 
This paper is a post-print of a paper submitted to and accepted for publication in IEEE Transaction on Power Delivery and is subject to Institution of Electrical and Electronic Engineering Copyright. The copy of record is available at IEEE Xplore Digital Library

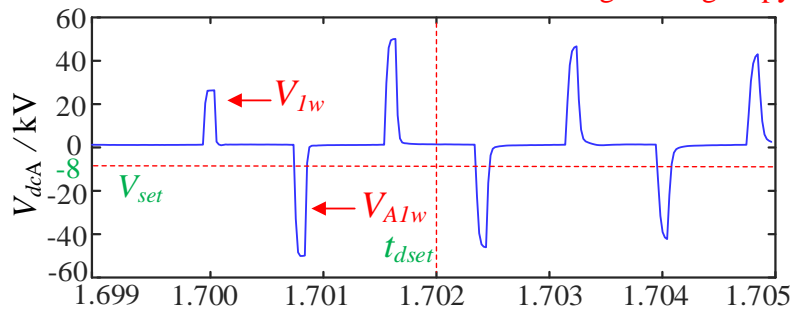

(a) $V_{d c A}$ under metallic permanent PTP fault

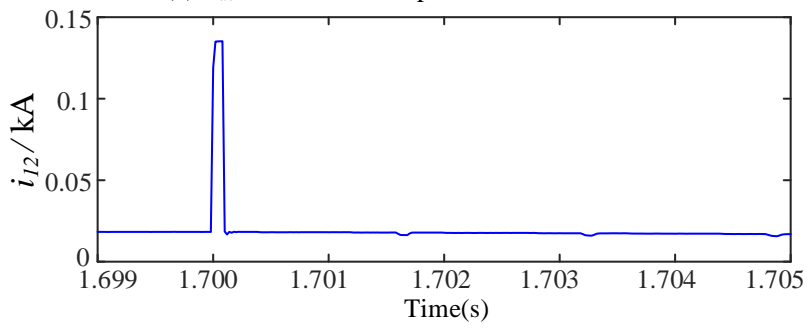

(b) $i_{12}$ under metallic permanent PTP fault

Fig. 13. Simulation waveform under metallic permanent PTP fault.

As can be seen from Fig. 13(a), the injected voltage $V_{l w}$ propagates towards node $B$. At the fault point (1/2 of OHL12), $V_{l w}$ is negatively reflected $(\alpha=0, \beta=-1)$ and the reflected wave travels back to node $A$. Then, a total positive reflection of the voltage wave $(\alpha=1, \beta=2)$ occurs at point $A$. As can be seen, the first refracted voltage $V_{A 1 w}$ detected at node $A$ is negative. The amplitude of $V_{A 1 w}$ is $-52.426 \mathrm{kV}(<-8 \mathrm{kV})$, and the detection time $t_{d}=0.8 \mathrm{~ms}\left(t_{d}=t_{1}-t_{0}=1.70088 \mathrm{~s}-1.70008 \mathrm{~s}=0.0008 \mathrm{~s}<2.0 \mathrm{~ms}\right)$, which satisfies the criteria for the permanent faults. Thus, the fault is identified as permanent and the DCCBs will not reclose. The measured fault distance $D_{\text {fault }}$ is $120 \mathrm{~km}$ $\left(D_{\text {faul }}=0.5 \times t_{d} \times v=0.5 \times 0.8 \times 300=120 \mathrm{~km}\right)$.

In Fig. 13 (b), the amplitude of current $i_{12}$ is $0.1378 \mathrm{kA}$, which is much less than $3.12 \mathrm{kA}$ (rated current). Hence, the temporary turning-on of transfer branch will not cause the second overcurrent to power electronic devices.

In order to verify the feasibility of the proposed method, the various metallic permanent PTP faults with different fault distances are applied and the results are shown in Table 3.

Table 3 Simulation results under metallic permanent PTP faults

\begin{tabular}{c||cccc}
\hline location $(\mathrm{km})$ & $V_{A l w}(\mathrm{kV})$ & $t_{d}(\mathrm{~ms})$ & Fault location $(\mathrm{km})$ & error \\
\hline \hline 30 & -53.85 & 0.18 & 27 & $-1.25 \%$ \\
60 & -53.21 & 0.36 & 54 & $-2.5 \%$ \\
90 & -52.88 & 0.56 & 84 & $-2.5 \%$ \\
150 & -52.41 & 0.98 & 147 & $-1.25 \%$ \\
180 & -52.35 & 1.18 & 177 & $-1.25 \%$ \\
210 & -51.64 & 1.38 & 207 & $-1.25 \%$ \\
240 & -50.87 & 1.6 & 240 & $0 \%$ \\
\hline
\end{tabular}

The results shown in Table 3 indicate that this method can effectively identify metallic permanent PTP faults. In addition, the scheme is effective for fault location, and the maximum percentage error is no more than $2.5 \%$.

3) Performance under Metallic Non-Permanent PTP Faults

At $1.5 \mathrm{~s}$, a metallic non-permanent PTP fault that lasts for $0.1 \mathrm{~s}$ is applied in the middle of OHL12. The voltage wave measured at node $A$ is shown in Fig. 14.

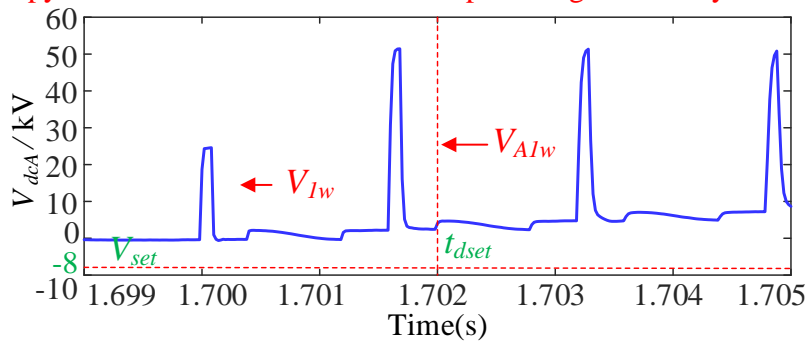

Fig. 14. Voltage waveforms under metallic non-permanent PTP fault.

In Fig. 14, the voltage wave $V_{l w}$ propagates towards node B. A total positive reflection of the voltage wave occurs at the end of OHL12 $(\alpha=1, \beta=2)$. Subsequently, the reflected wave propagates back to node $A$. Later, a second positive total reflection of voltage wave $(\alpha=1, \beta=2)$ appears at node A. Since the amplitude of $V_{A 1 w}$ is always greater than $-8 \mathrm{kV}$ within $2 \mathrm{~ms}$, the fault is deemed as a non-permanent fault.

B. Validation of Adaptive Reclosing for MMC based DC Grid 1) Determination of Setting Value for Fault Identification

At 2.0s, a metallic permanent PTP fault is applied at $75 \%$ of OHL12. After 2ms detection delay, DCCB 12 and DCCB 21 are tripped and fault current gradually decreases to zero. After deionization of OHL12, the transfer branch of DCCB 12 is turned on for $0.1 \mathrm{~ms}$ at $2.2 \mathrm{~s}$. The DC terminal voltage of $\mathrm{MMC1}$, the voltage across the current limiting inductor and the DC line voltage at point $A$ are shown in Fig. 15 (a)-(c). The current waveform of $I_{d c 12}$ is shown Fig. 15 (d).

As can be seen, due to the voltage drop on the current limiting inductor, the amplitude of the voltage pulse injected into the faulted line $\left(V_{d c A}\right)$ is $104 \mathrm{kV}$. And the amplitude of DC line current $\left(I_{d c 12}\right)$ increases to $0.29 \mathrm{kA}$. This current will not result in the damage of power electronics. According to the threshold setting principle in the two-terminal MMC-HVDC case, the setting value $V_{\text {set }}$ is calculated: $V_{\text {set }}=V_{\text {Alwmax }} \times k_{\text {rel }}=-$ $80.48 \times 0.6 \approx-48 \mathrm{kV}$.

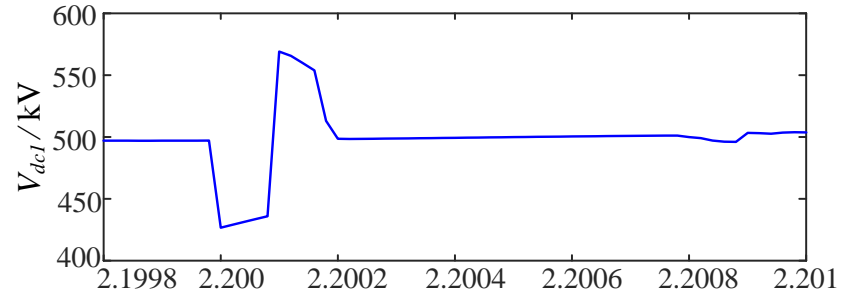

(a) DC terminal voltage of $\mathrm{MMC1}$

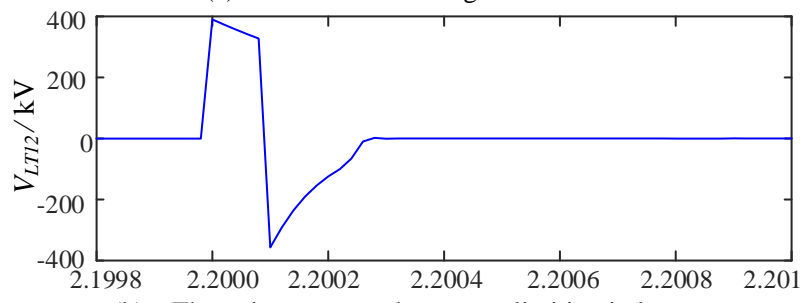

(b) The voltage across the current limiting inductor

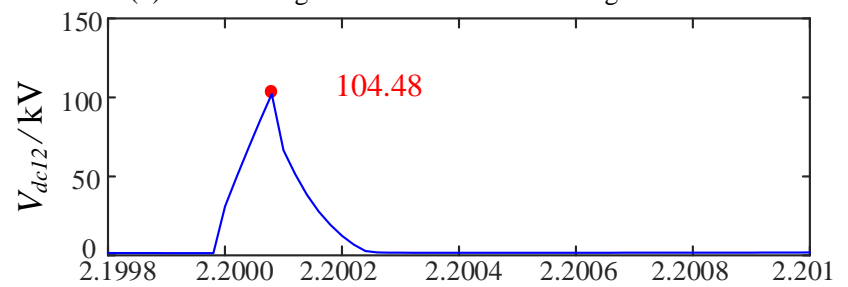


This paper is a post-print of a paper submitted to and accepted for publication in IEEE Transaction on Power Delivery and is subject to Institution of Electrical and Electronic Engineering Copyright. The copy of record is available at IEEE Xplore Digital Library

(c) DC line voltage at point $A$

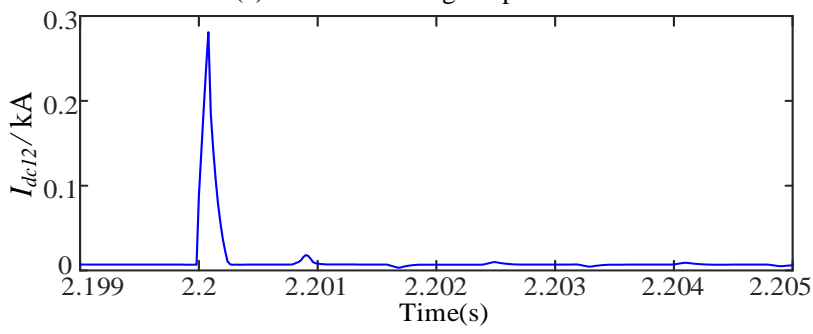

(d) Waveform of current $I_{d c l 2}$

Fig. 15. DC voltages and current during adaptive reclosing.

2) Performance under Permanent PTP Fault with High Resistance

To evaluate the performance of the proposed method for MMC based DC grids, apply a permanent PTP fault with $100 \Omega$ resistance in the middle of OHL12 at 2.0s. After deionization of OHL 12, DCCB 12 are turned on to inject a voltage pulse into the faulted lines at $2.2 \mathrm{~s}$ and the voltages $V_{d c A}$ is measured, as shown in Fig. 16 (a).

In Fig. 16 (a), the voltage $V_{A 1 w}$ is $-144 \mathrm{kV}(<-48 \mathrm{kV})$, and the detection time $t_{d}$ is $0.84 \mathrm{~ms}(<2 \mathrm{~ms})$. Thus, the fault is deemed to be permanent and it demonstrates that the proposed method can identify the fault characteristics correctly.

In order to test the impact of the pulse injection on healthy parts, the DC output voltages and active power of each station under the permanent fault are measured, as shown in Fig. 16 (b) and Fig. 16 (c). As can be seen, the DC terminal voltages of each station can maintain the steady values and the power transmission of healthy parts will not be interrupted. It demonstrates that the pulse injection has no impact on healthy parts.

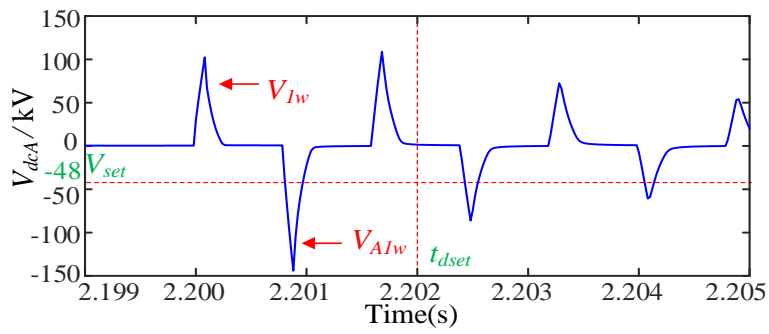

(a) $V_{d c A}$ under a permanent PTP fault

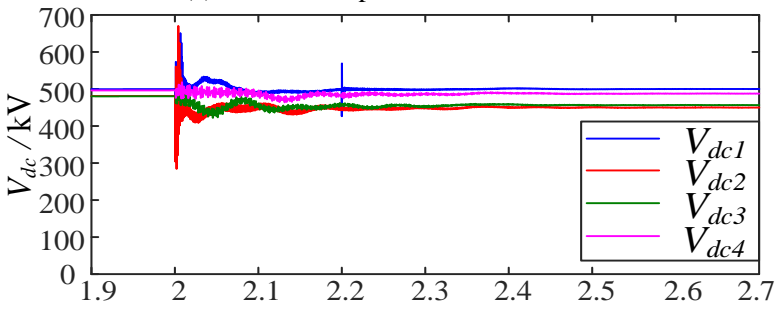

(b) DC terminal voltages of each station under permanent fault

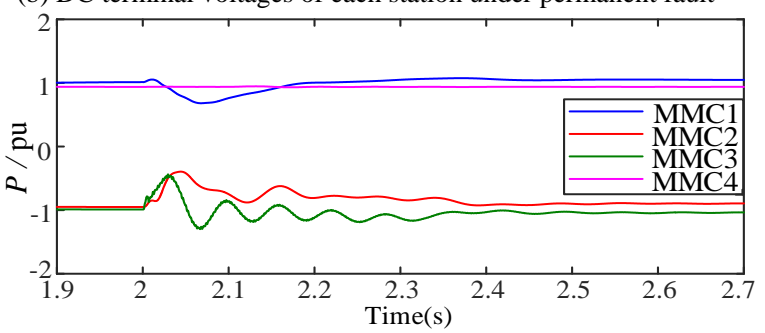

(c) Active power of each station under permanent fault

Fig. 16. Simulation waveforms under high-resistance permanent PTP fault.
3) Performance under Non-Permanent PTP Fault with High Resistance

Apply a nonpermanent PTP fault with $100 \Omega$ resistance at the same location at 2.0s. After deionization of OHL 12, DCCB 12 are turned on to inject a voltage pulse into the faulted lines at $2.2 \mathrm{~s}$. The measured voltages $V_{d c A}$ is shown in Fig. 17.

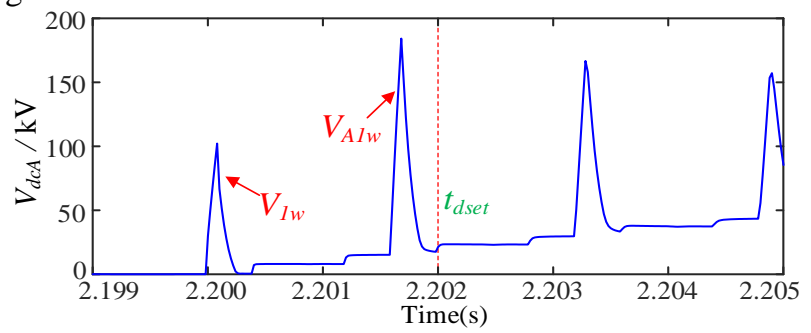

Fig. 17. $V_{d c A}$ under high-resistance non-permanent PTP fault.

In Fig. 17, the amplitude of $V_{A 1 w}$ is always larger than $-48 \mathrm{kV}$ within $2 \mathrm{~ms}$, the fault is deemed as a non-permanent fault.

\section{ROBUSTNESS EVALUATION}

Taking the two-terminal MMC-HVDC system as an example, this section will test the performance of adaptive reclosing versus different fault resistances, noise disturbance and different current-limiting inductances.

A. Influence of Fault Resistance

At $1.5 \mathrm{~s}$, a permanent PTP fault with $100 \Omega$ fault resistance is applied in the middle of OHL12. At 1.7s, MMC1P and MMC1N inject a voltage pulse into the OHL12. The voltage measured at node $A$ is shown in Fig. 18(a).

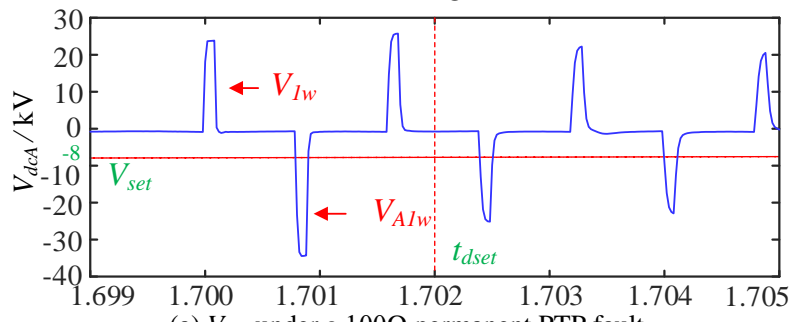

(a) $V_{d c A}$ under a $100 \Omega$ permanent PTP fault

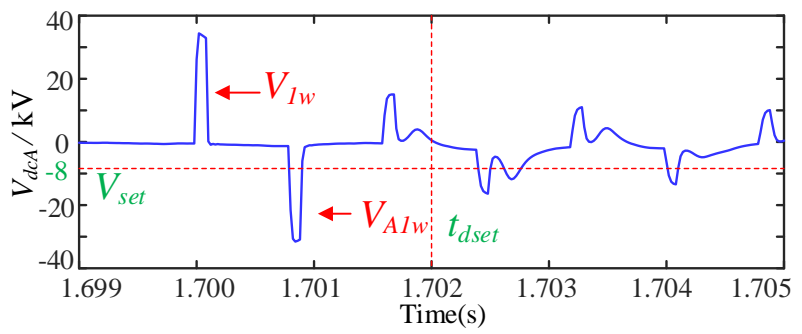

(b) $V_{d c A}$ under a $100 \Omega$ permanent P-PTG fault

Fig. 18. Voltage waveforms under a $100 \Omega$ permanent fault.

As can be seen from Fig. 18(a), $V_{A 1 w}$ is $-33.776 \mathrm{kV}(<-8 \mathrm{kV})$, and the detection time $t_{d}$ is $0.76 \mathrm{~ms}(<2 \mathrm{~ms})$, so the fault is identified as permanent. In addition, the measured fault distance $D_{\text {fault }}$ is $114 \mathrm{~km}$.

To further verify the robustness of the proposed scheme, different permanent PTP faults with different distances and resistances are applied, the results are shown in Table 4 . The results show the fault resistances will not affect the identification of the proposed scheme.

Table 4 Results under permanent PTP faults with different resistances. \begin{tabular}{l||l|lll} 
resistance $(\Omega)$ & location $(\mathrm{km})$ & $V_{A l w}(\mathrm{kV})$ & $t_{d}(\mathrm{~ms})$ & location $(\mathrm{km})$ \\
\hline
\end{tabular} 
This paper is a post-print of a paper submitted to and accepted for publication in IEEE Transaction on Power Delivery and is subject to Institution of Electrical and Electronic Engineering Copyright. The copy of record is available at IEEE Xplore Digital Library

\begin{tabular}{c||c|ccc}
\hline \multirow{3}{*}{50} & 30 & -41.481 & 0.16 & 24 \\
& 90 & -41.18 & 0.56 & 84 \\
& 180 & -40.42 & 1.18 & 177 \\
\cline { 2 - 5 } 200 & 30 & -25.804 & 0.16 & 24 \\
& 90 & -22.55 & 0.56 & 84 \\
& 180 & -22.45 & 1.2 & 180 \\
\hline
\end{tabular}

\section{B. The Influence of Noise}

At $1.5 \mathrm{~s}$, a non-permanent metallic PTP fault and a permanent PTP fault with $100 \Omega$ resistance are applied in the middle of OHL12 respectively. To test the robustness to the noise, a white-noise with $10 \mathrm{db}$ pulse-to-noise ratio is added in the measured pulse $V_{d c A}$ and the simulation results are shown in Fig. 19.

In Fig. 19(a), $V_{A l w}$ is negative and its value is smaller than $-8 \mathrm{kV}$. Thus, the fault is deemed to be permanent. In Fig. 19(b), $V_{A I w}$ is always positive within $2 \mathrm{~ms}$, so the fault is identified to be non-permanent.

The simulations demonstrate that the proposed method for fault identification is robust to noise. However, the noise will affect the measurement of $t_{\mathrm{d}}$, resulting in the decrease in the accuracy of the fault location.

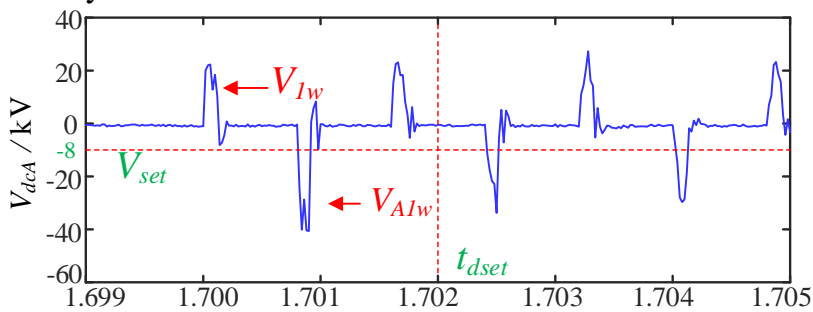

(a) $V_{d c A}$ under a permanent PTP fault with $10 \mathrm{db}$ noise

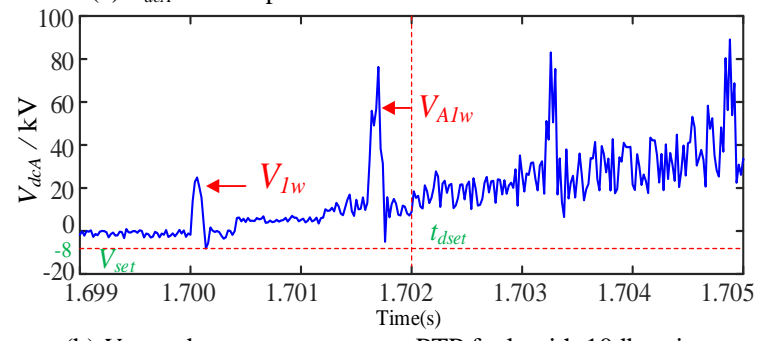

(b) $V_{d c A}$ under a non-permanent PTP fault with $10 \mathrm{db}$ noise

Fig. 19. Voltage waveforms under $10 \mathrm{db}$ noise.

\section{The Influence of the Current-limiting Reactor}

To evaluate the influence of current-limiting reactor $L_{d c}$ on the proposed scheme, different reactors varying from $50 \mathrm{mH}$ to $150 \mathrm{mH}\left(L_{d c}=50 \mathrm{mH}, 100 \mathrm{mH}, 150 \mathrm{mH}\right)$ are tested. Fig. 20 shows the waveforms of $V_{d c A}$ under P-PTG and PTP faults with $100 \Omega$ resistance applied in the middle of OHL12 respectively.

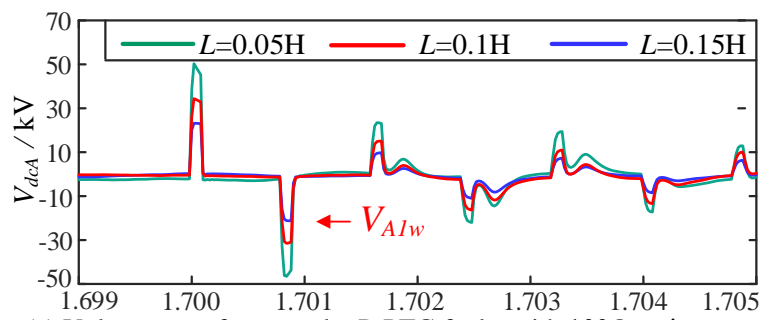

(a) Voltage waveforms under P-PTG faults with $100 \Omega$ resistance

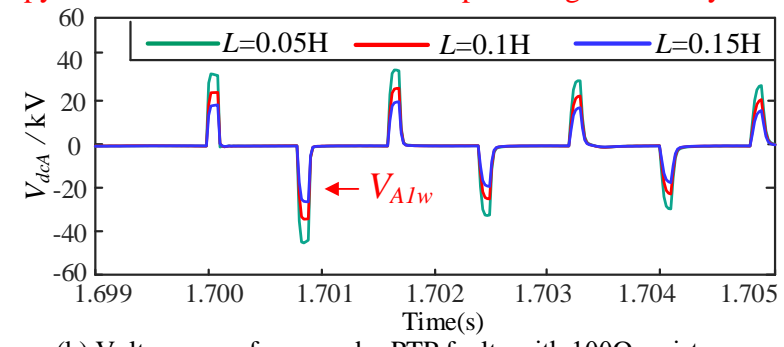

(b) Voltage waveforms under PTP faults with $100 \Omega$ resistance Fig. 20. Voltage waveforms under different faults.

As shown in Fig. 20, the amplitude of $V_{d c A}$ decreases with the increase of current-limiting inductance. However, the accuracy of the proposed method is not affected by the currentlimiting reactor.

\section{DisCUSSION ON ADAPTIVE RECLOSING SCHEME USING Two Ends Voltage PULSE INJECTION}

The adaptive reclosing scheme mentioned above injects the voltage pulse from a single converter (single-end voltage injection). However, since the traveling wave method is applied, the single-end voltage injection may be disturbed by the close-in faults, namely, the faults happened on the head of the transmission lines ( $0 \%$ of OHL 12 for MMC1). To deal with the close-in faults, the voltage pulse injection from both ends are evaluated and discussed for the two-terminal HVDC system and the DC grids.

\section{A. Principle of Two Ends Pulse Injection}

After the deionization of OHL, MMC1 and MMC2 inject the voltage pulses $V_{l w_{-} A}$ and $V_{l w_{-} B}$ into the faulted line simultaneously, as shown in Fig. 21. When the voltage waves arrive at node $C$, they will be reflected and refracted.

Depending on different fault distances $\left(D_{\text {fault }}\right)$, three scenarios are analyzed.

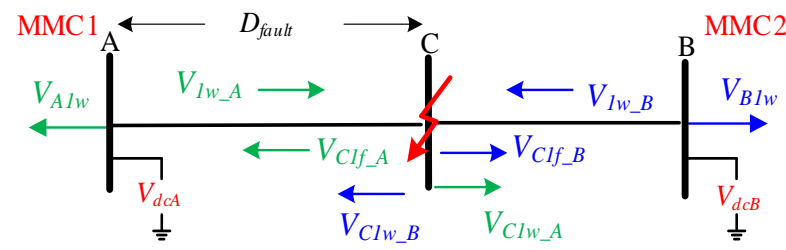

Fig. 21. Fault identification using the two ends voltage pulse injection.

I. $D_{\text {fault }}$ is less than $120 \mathrm{~km}\left(D_{\text {faul }} / D_{A B}<50 \%\right)$.

Since $D_{\text {fault }}$ is less than $120 \mathrm{~km}$, the reflected voltage $V_{C l f_{-} A}$ (negative) will arrive at node $A$ earlier than the refracted voltage $V_{C I w_{-} B}$ (positive). Thus, the first detected refracted voltage $V_{A l w}$ is from $V_{C l f-A}$, which is negative, as shown in Fig. 22 (a).

Specially, for the close-in faults ( $D_{\text {fault }}$ is close to $0 \mathrm{~km}$ ), the refracted voltage $V_{A I w}$ cannot be detected correctly at node $A$. However, by injecting voltage pulse from node $B$, these faults can be identified by measuring the refracted voltage $V_{B I w}$ at node $B$. Then, node $A$ will receive the identification result through a fast communication channel.

II. $D_{\text {fault }}$ is larger than $120 \mathrm{~km}\left(D_{\text {fault }} / D_{A B}>50 \%\right)$.

Since $D_{\text {fault }}$ is larger than $120 \mathrm{~km}$, the refracted voltage $V_{C l w_{-} B}$ (positive) will arrive at node $A$ earlier than the reflected voltage $V_{C l f_{-} A}$ (negative). Thus, the first detected refracted 
This paper is a post-print of a paper submitted to and accepted for publication in IEEE Transaction on Power Delivery and is subject to Institution of Electrical and Electronic Engineering Copyright. The copy of record is available at IEEE Xplore Digital Library

voltage $V_{A I w}$ is from $V_{C l w_{-} B}$, which is positive. And the second detected refracted voltage is from $V_{C l f_{-} A}$, which is negative, as shown in Fig. 22 (b). And the detection time for the negative refracted voltage is still less than $2.0 \mathrm{~ms}$.

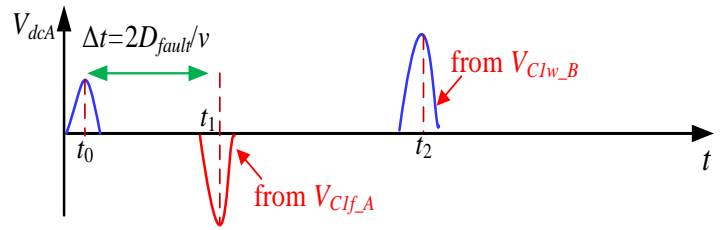

(a) The fault distance is less than $50 \%$ of the OHL12

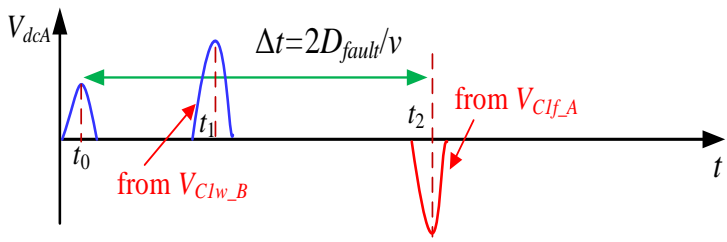

(b) The fault distance is larger than $50 \%$ of the OHL12

Fig. 22. Traveling wave process using the two ends voltage pulse injection method.

III. $D_{\text {faul }}$ is equal to $120 \mathrm{~km}\left(D_{\text {fault }} / D_{A B}=50 \%\right)$.

When $D_{\text {fault }}$ is equal to $120 \mathrm{~km}$, the reflected voltage $V_{C l f_{-} A}$ (negative) and the refracted voltage $V_{C l w_{-} B}$ (positive) will arrive at node $A$ at the same time. The measured voltage $V_{A l w}$ under permanent faults can be expressed as:

$$
\begin{aligned}
V_{A l w} & =\alpha_{A}\left(V_{C l f_{-} A}+V_{C l w_{-} B}\right)=\alpha_{A}\left(\beta_{C} V_{l w_{-} A}+\alpha_{C} V_{l w_{-} B}\right) \\
& =2\left(\beta_{C} V_{l w_{-} A}+\alpha_{C} V_{l w_{-} B}\right)=\frac{2\left(R_{g} V_{l w_{-} B}-Z_{C} / 2 V_{l w_{-} A}\right)}{R_{g}+Z_{C} / 2}
\end{aligned}
$$

As can be seen, when the amplitudes of two injected voltage pulses are the same $\left(V_{l w_{-} A}=V_{l w_{-} B}\right), V_{A l w}$ will always be a negative value if equation (13) holds true, which is the same as scenario $I$. Thus, the faults with low resistances at mid-point of faulted lines can be correctly identified.

$$
R_{g}<Z_{C} / 2
$$

When the fault resistance $R_{g}$ is larger than $Z_{C} / 2, V_{A l w}$ will become positive, which will cause false identification.

To deal with the high-resistance faults on mid-line, for the two-terminal HVDC systems, the amplitudes of voltage pulses generated from MMC 1 and MMC 2 should not be the same. Namely, the coefficients $k$ for MMC 1 and MMC2 should be different. If the amplitude of $V_{l w_{-} A}$ is larger than $V_{l w_{-} B}$, the identification is similar to that of scenario $I$.

For the DC grids, since the coefficients $k$ is fixed $(k=1)$, the amplitudes of voltage pulses generated from MMC 1 and MMC 2 cannot be changed. A feasible approach to address this problem is to vary the injection time between the two ends. However, a coordination strategy between two ends needs to be deliberately designed, such as adopting an injection time interval of $2 D_{A B} / v$.

To be concluded, the evaluation of different injection methods for the two-terminal HVDC system and the DC grids are shown in Table 5.

Table 5 Evaluation of different voltage pulse injection method

\begin{tabular}{c|c|c|c}
\hline \multicolumn{2}{c|}{ Injection methods } & Two-terminal HVDC & DC grid \\
\hline \multicolumn{2}{c|}{$\begin{array}{l}\text { Single-end with } \\
\text { communication }\end{array}$} & $\begin{array}{c}\text { Suitable for whole line } \\
\text { except close-in faults }\end{array}$ & $\begin{array}{c}\text { Suitable for whole line } \\
\text { except close-in faults }\end{array}$ \\
\hline Two ends & without & Suitable for whole line & Suitable for whole line \\
\hline
\end{tabular}

\begin{tabular}{|c|c|c|}
\hline communication & except close-in faults & except close-in faults \\
\hline $\begin{array}{c}\text { with } \\
\text { communication }\end{array}$ & Suitable for whole line & Suitable for whole line \\
\hline
\end{tabular}

The criterion for fault identification based on two ends injection is shown in equation(14). For MMC1, fault characteristics can be identified by detecting the negative refracted voltage at node $A$; for MMC2, fault characteristics can be identified by detecting the negative refracted voltage at node $B$. It should be noted that the management of mid-line high-resistance faults is not included in equation (14) since it is beyond the research content of this paper.

$$
\left\{\begin{array}{lll}
\text { For } \mathrm{MMC} 1 \Rightarrow V_{d c A}<V_{\text {set }} & \text { and } & t_{d_{-} 1}<2.0 \mathrm{~ms} \\
\text { For MMC2 } \Rightarrow V_{d c B}<V_{\text {set }} & \text { and } & t_{d_{-} 2}<2.0 \mathrm{~ms}
\end{array}\right.
$$

B. Validation of Two Ends Pulse Injection for the TwoTerminal HVDC Systems

To verify the effectiveness of the two ends voltage pulse injection method, a permanent PTP fault with $100 \Omega$ fault resistance is applied at $25 \%$ of OHL12 at $1.5 \mathrm{~s}$ in the twoterminal HVDC systems. At 1.7s, MMC1 and MMC2 inject voltage pulses into OHL12. The voltages measured at node $A$ and node $B$ are shown in Fig. 23.

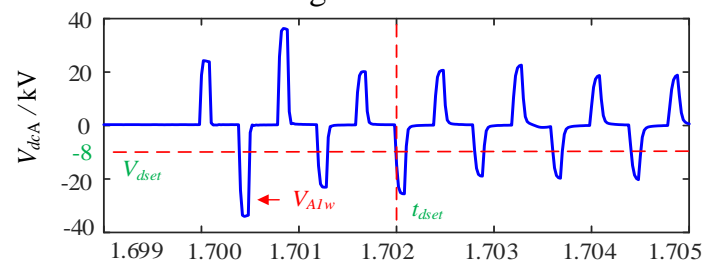

(a) The voltage $V_{d c A}$ measured at node $A$

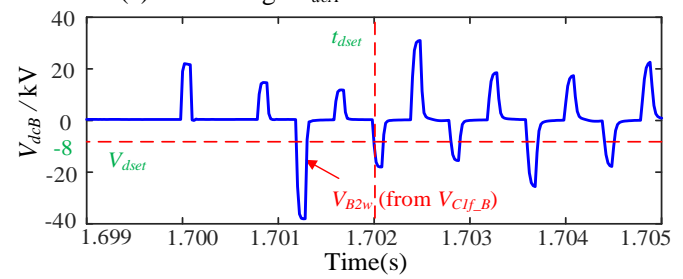

(b) The voltage $V_{d c B}$ measured at node $B$

Fig. 23. Measured voltages using two ends injection method for twoterminal HVDC systems.

In Fig. 23, for MMC1, a negative voltage $V_{A l w}(-36 \mathrm{kV})$ can be detected within $0.42 \mathrm{~ms}$; For MMC2, a negative voltage $V_{B 2 w}(-38.7 \mathrm{kV})$ can be detected within $1.24 \mathrm{~ms}$. Thus, the fault can be identified to be permanent for MMC1 and MMC2 respectively.

Since the fault is near MMC1, the refracted voltage $V_{C 1 w_{-} A}$ will arrive at node $B$ earlier comparing with the reflected voltage $V_{C l f_{-} B}$. However, the negative refracted voltage from $V_{C I f_{-} B}$ can still be detected within $2 \mathrm{~ms}$.

\section{Validation of Two Ends Pulse Injection for DC Grids \\ 1) Close-in Faults}

To verify the effectiveness of the two ends pulse injection under closed-in faults, a permanent PTP fault with $100 \Omega$ fault resistance is applied at $100 \%$ of OHL12 at 2.0s in the DC grid model (it is a close-in fault for MMC2). At 2.2s, MMC1 and MMC2 inject voltage pulses into OHL12. The voltages measured at node $A$ and node $B$ are shown in Fig. 24. 
This paper is a post-print of a paper submitted to and accepted for publication in IEEE Transaction on Power Delivery and is subject to Institution of Electrical and Electronic Engineering Copyright. The copy of record is available at IEEE Xplore Digital Library

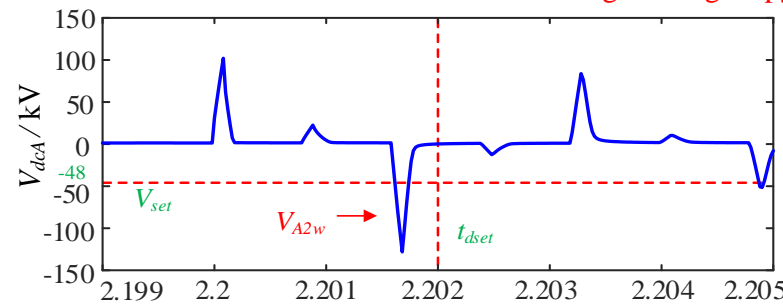

(a) $V_{d c A}$ under the fault at $100 \%$ of OHL12

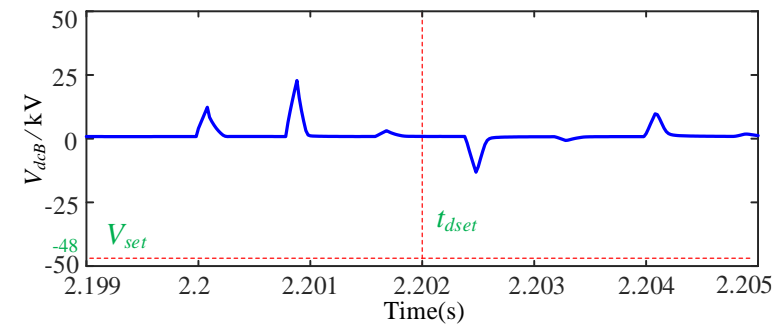

(b) $V_{d c B}$ under the fault at $100 \%$ of OHL12

Fig. 24. The measured voltages based on the two ends injection method for MMC based DC grids under closed-in faults.

As can be seen in Fig. 24(a), a negative voltage $V_{A 2 w}$ ($132 \mathrm{kV}$ ) can be detected within $1.6 \mathrm{~ms}$. Thus, the fault can be identified to be permanent for MMC1. For MMC2, since the fault distance is $0 \mathrm{~km}$, the voltage pulse injection method will not work, as shown in Fig. 24 (b). Thus, the reclosing order for MMC2 will be received from MMC1 through fast communication channel.

2) Mid-point Faults

Apply permanent PTP faults with $0.01 \Omega$ and $100 \Omega$ fault resistance at $50 \%$ of $\mathrm{OHL} 12$ at $2.0 \mathrm{~s}$ respectively. At $2.2 \mathrm{~s}$, MMC1 and MMC2 inject voltage pulses into OHL12. The voltages measured at node $A$ are shown in Fig. 25.

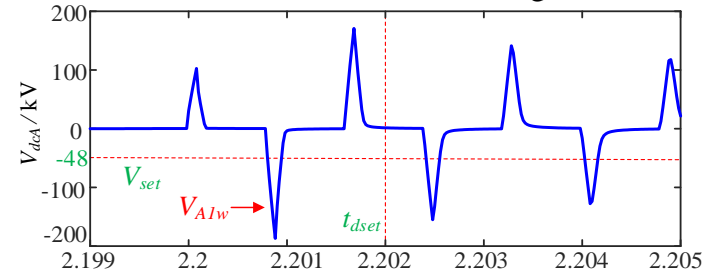

(a) $V_{d c A}$ under $0.01 \Omega$ fault at $50 \%$ of OHL12

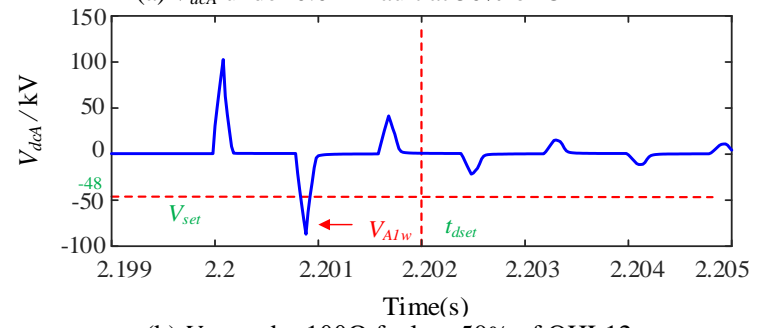

(b) $V_{d c A}$ under $100 \Omega$ fault at $50 \%$ of OHL12

Fig. 25. Measured voltages using two ends injection method for DC grids.

In Fig. 25(a), since the fault resistance is $0.01 \Omega$, the refracted voltage $V_{C l w_{-} B}$ is near zero according to equation(5). Thus, only the refracted voltage $V_{C l f_{-} A}$ will arrive at node $A$, which is similar to single-end injection. And the fault can be identified to be permanent correctly.

In Fig. 25(b), the refracted voltage $V_{C I w_{-} B}$ will increase with the increase of fault resistance. The positive $V_{C I w_{-} B}$ and negative $V_{C l f \_} A$ will arrive at node $A$ at the same time. However, in this paper, the wave impedance $Z_{C}$ obtained from the Line Constant Program in PSCAD/EMTDC software is $370 \Omega$.
According to equation(12), a negative voltage $V_{A l w}(-87 \mathrm{kV})$ will be measured within $0.8 \mathrm{~ms}$. Thus, the fault can be identified to be permanent correctly.

\section{CONCLUSION}

This paper proposes adaptive reclosing schemes based on active pulse injection for the two-terminal HB MMC-HVDC systems and the MMC based meshed DC grids. By turning on the transfer branch of DCCB for $0.1 \mathrm{~ms}$, the voltage pulse is injected into the faulted lines and the fault characteristics are identified by measuring the refracted voltage. Aimed at covering all fault locations, the single-end and two ends voltage pulse injection methods are proposed respectively.

The proposed schemes can avoid second damage to the system and decrease the breaking capacity of DCCBs. Since the amplitude of the injected pulse is small and the turning-on time of transfer branch is short, it will not cause overcurrent to power electronic devices. In addition, this method is robust to fault types and fault resistance. The noise will decrease the accuracy of fault location but have no influence on the accuracy of fault identification. Quantities of simulation results demonstrate that the current-limiting reactor will result in the attenuation of the refracted voltage amplitude but have no impact on the accuracy of the proposed scheme. This method can be well applied to other hybrid DCCB and converter topologies.

\section{REFERENCES}

[1] J. Freytes, S. Akkari, P. Rault, et al, "Dynamic Analysis of MMC-Based MTDC Grids: Use of MMC Energy to Improve Voltage Behavior," IEEE Trans. Power Del., vol. 34, no. 1, pp. 137-148, Feb. 2019.

[2] C. M. Franck, "HVDC Circuit Breakers: A Review Identifying Future Research Needs," IEEE Trans. on Power Del., vol. 26, no. 2, pp. 9981007, Apr. 2011.

[3] Häfner J, Jacobson B, "Proactive Hybrid HVDC Breakers-A key innovation for reliable HVDC grids," CIGRE Session, Italy, Bologna: CIGRE, 2011:1-8.

[4] Grieshaber W, Dupraz J P, Penache D L, et al. "Development and test of a $120 \mathrm{kV}$ direct current circuit breaker," CIGRE Session, Paris, France: CIGRE, 2014:1-10.

[5] W. Zhou, et al, "Development and test of a $200 \mathrm{kV}$ full-bridge based hybrid HVDC breaker," $201517^{\text {th }}$ European Conference on Power Electronics and Applications (EPE'15 ECCE-Europe), Geneva, 2015, pp. 1-7.

[6] B. Li, Q. Hao and X. Yin, "Study on Transient Electrical Characteristics of DC Circuit Breaker Based on IGBT Composite Model," 2018 IEEE International Power Electronics and Application Conference and Exposition (PEAC), Shenzhen, 2018, pp. 1-5.

[7] M. Kong, X Pei, H Pang, et al, "A lifting wavelet-based protection strategy against DC line faults for Zhangbei HVDC Grid in China," 2017 $19^{\text {th }}$ European Conference on Power Electronics and Applications (EPE'17 ECCE Europe), Warsaw, 2017, pp. P.1-P.11.

[8] W. Xiang, W. Lin, T. An, et al, "Equivalent Electromagnetic Transient Simulation Model and Fast Recovery Control of Overhead VSC-HVDC Based on SB-MMC," IEEE Trans. Power Del., vol. 32, no. 2, pp. 778788, Apr. 2017.

[9] G. Adam. R. Li, D. Holliday, S. Finney, et al, "Continued Operation of Multi-Terminal HVDC Networks Based on Modular Multilevel Converters," Proc. CIGRE, 2015, pp.1-8.

[10] X. Ding, G. Tang, M. Han, et al, "Characteristic Parameters Extraction and Application of the Hybrid DC Circuit Breaker in MMC-HVDC," Power System Technology, vol. 38, no.1, pp. 309-319, Jan. 5, 2018.

[11] Y. Ge, F. Sui, Y. Xiao, "Prediction methods for preventing single-phase reclosing on permanent fault," IEEE Trans. Power Del., vol. 4, no. 1, pp. 114-121, Jan. 1989.

[12] L. Shang and J. Lv, "A new approach for identification of the fault type 
This paper is a post-print of a paper submitted to and accepted for publication in IEEE Transaction on Power Delivery and is subject to Institution of Electrical and Electronic Engineering Copyright. The copy of record is available at IEEE Xplore Digital Library on transmission lines," The $20142^{\text {nd }}$ International Conference on Systems and Informatics (ICSAI 2014), Shanghai, 2014, pp. 132-136.

[13] X. Luo, C. Huang, Y. Jian, et al, "Adaptive single-phase reclosure scheme for transmission lines with shunt reactors based on current inner product," IET Gener. Transm. Dis., vol. 11, no. 7, pp. 1770-1776, May. 2017.

[14] D. Lin, H. Wang, D. Lin, et al, "An Adaptive Reclosure Scheme for Parallel Transmission Lines with Shunt Reactors," IEEE Trans. Power Del., vol. 30, no. 6, pp. 2581-2589, Dec. 2015.

[15] S. Ahn, C. Kim, R. K. Aggarwal, et al, "An alternative approach to adaptive single pole auto-reclosing in high voltage transmission systems based on variable dead time control," IEEE Trans. Power Del., vol. 16, no. 4, pp. 676-686, Oct. 2001.

[16] J. Shu, S. Wang and T. Liu, "A Soft Reclosing Model for Hybrid DC Circuit Breaker in VSC-MTDC System," 2018 IEEE $4^{\text {th }}$ Southern Power Electronics Conference (SPEC), Singapore, Singapore, 2018, pp. 1-5.

[17] K. Vinothkumar, I. Segerqvist, N. Johannesson and A. Hassanpoor, "Sequential auto-reclosing method for hybrid HVDC breaker in VSC HVDC links," 2016 IEEE $2^{\text {nd }}$ Annual Southern Power Electronics Conference (SPEC), Auckland, 2016, pp. 1-6.

[18] M. Stumpe, P. Ruffing, P. Wagner and A. Schnettler, "Adaptive SinglePole Autoreclosing Concept with Advanced DC Fault Current Control for Full-Bridge MMC VSC Systems," IEEE Trans. Power Del., vol. 33, no. 1, pp. 321-329, Feb. 2018.

[19] G. Song, T. Wang and S. T. H. Kazmi, "DC Line Fault Identification Based on Pulse Injection from Hybrid HVDC Breaker," IEEE Trans. Power Del., vol. 30, no. 6, pp. 2581-2589, Dec. 2015.

[20] T. Bi, S. Wang and K. Jia, "Single pole-to-ground fault location method for MMC-HVDC system using active pulse," IET Gener. Transm. Dis., vol. 42, no. 12, pp. 4015-4021, Dec. 2018.

[21] W. Xiang, W. Lin, L. Xu, et al, "Enhanced Independent Pole Control of Hybrid MMC-HVDC System," IEEE Trans. Power Del., vol. 33, no. 2, pp. 861-872, Apr. 2018.

[22] J. Sneath and A. D. Rajapakse, "Fault Detection and Interruption in an Earthed HVDC Grid Using ROCOV and Hybrid DC Breakers," IEEE Trans. Power Del., vol. 31, no. 3, pp. 973-981, Jun. 2016.

[23] W. Xiang, S. Yang, L. Xu, et al, “A Transient Voltage based DC Fault Line Protection Scheme for MMC based DC Grid Embedding DC Breakers," IEEE Trans. Power Del., vol. 34, no. 1, pp. 334-345, Feb. 2019.

[24] G. Song, T. Wang, C. Zhang, et al, "Adaptive Auto-reclosing of DC Line Based on Characteristic Pulse Injected by FB-MMC," Power System Technology, vol. 43, no.1, pp. 143-156, Jan., 2019.

[25] P. Kundur, Power System Stability and Control. New York: McGrawHill, 1994.

\section{BIOGRAPHIES}

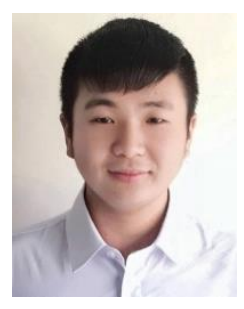

Saizhao Yang obtained his B.E. degree in electrical engineering from Huazhong University of Science and Technology (HUST), China, in 2018. He is currently pursuing his $\mathrm{PhD}$ degree at HUST. His research interests include dc fault protection of MMC-HVDC and dc grids.

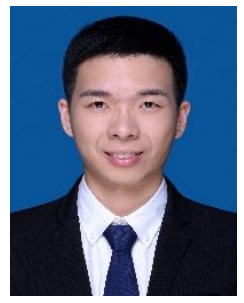

Wang Xiang (S'16-M'17) received his B.Eng. and PhD degrees both in electrical engineering from Huazhong University of Science and Technology (HUST), China in 2012 and 2017 respectively. He was a visiting student at the University of Aberdeen and the University of Strathclyde in 2014 and 2016 respectively. Currently, he is a research associate at the University of Strathclyde. His main research interests include MMCHVDC, high power dc/dc converters and dc grids.

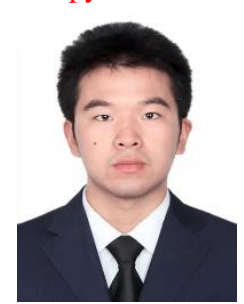

Xiaojun Lu (M'19) received his B.Eng and Ph.D degree both in electrical engineering from Huazhong University of Science and Technology (HUST), Wuhan, China in 2013 and 2018, respectively. He is currently a post-doctor at HUST. His main research interests include modeling and stability analysis of VSC/MMCHVDC and DC grids.

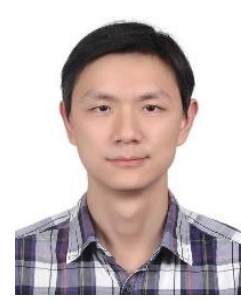

Wenping Zuo received the B.S. degree and Ph.D degree in electrical engineering from Huazhong University of Science and Technology (HUST), Wuhan, China, in 2009 and 2017, respectively. Currently he is a Post-Doctoral Research Fellow with HUST. His research interests include DC grid key equipment, energy storage, and renewable energy integration.

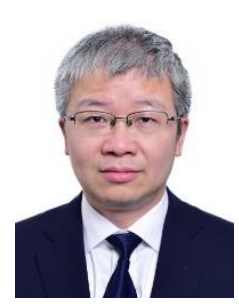

Jinyu Wen (M'10) received his B.Eng. and Ph.D degrees all in electrical engineering from Huazhong University of Science and Technology (HUST), Wuhan, China, in 1992 and 1998, respectively. He was a visiting student from 1996 to 1997 and research fellow from 2002 to 2003 all at the University of Liverpool, $\mathrm{UK}$, and a senior visiting researcher at the University of Texas at Arlington, USA in 2010. From 1998 to 2002 he was a director engineer in XJ Electric Co. Ltd. in China. In 2003 he joined the HUST and now is a Professor at HUST. His current research interests include renewable energy integration, energy storage application, DC grid, and power system operation and control. 